\title{
Progression of fibromyalgia: results from a 2-year observational fibromyalgia and chronic pain study in the US
}

\author{
Edgar H Adams' \\ Heather J McElroy ${ }^{2}$ \\ Margarita Udall ${ }^{3}$ \\ Elizabeth T Masters ${ }^{3}$ \\ Rachael M Mann ${ }^{4}$ \\ Caroline P Schaefer \\ Joseph C Cappelleri ${ }^{5}$ \\ Andrew G Clair ${ }^{3}$ \\ Markay Hopps ${ }^{3}$ \\ Shoshana R Daniel ${ }^{6}$ \\ Philip Mease ${ }^{7,8}$ \\ Stuart L Silverman ${ }^{9,10}$ \\ Roland Staud"I \\ 'Covance Market Access Services Inc, \\ Gaithersburg, MD, USA; ${ }^{2}$ Covance \\ (Asia) Pte Ltd, Singapore, Singapore; \\ ${ }^{3}$ Pfizer Inc, New York, NY, ${ }^{4}$ Covance \\ Market Access Services Inc, San \\ Diego, CA, ${ }^{5}$ Pfizer Inc, Groton, CT, \\ ${ }^{6}$ Covance Market Access Services \\ Inc, Conshohocken, PA, ${ }^{7}$ Division of \\ Rheumatology Research, Swedish \\ Medical Center, Seattle, WA, \\ ${ }^{8}$ Department of Rheumatology, \\ University of Washington, Seattle, \\ WA, ${ }^{9}$ Department of Medicine, \\ Division of Rheumatology, Cedars- \\ Sinai Medical Center, Los Angeles, \\ CA, ${ }^{10}$ Department of Medicine, \\ University of California, Los Angeles, \\ CA, "Department of Medicine, \\ University of Florida, Gainesville, FL, \\ USA
}

Correspondence: Markay Hopps Pfizer Inc, 235 East 42nd Street, New York, NY 10017, USA

Tel + I 21273307I7

Email Markay.Hopps@pfizer.com
This article was published in the following Dove Press journal:

Journal of Pain Research

I June 2016

Number of times this article has been viewed

Background: A previous fibromyalgia (FM) research reports that $20 \%-47 \%$ of diagnosed patients may not meet the study definition of FM 1-2 years after diagnosis. The aim of this study was to gain a better understanding of the progression of FM in a geographically diverse cohort over a 2-year time period.

Methods: This cohort study followed 226 subjects recruited online to assess FM and chronic widespread pain (CWP) diagnosis stability over time. At enrollment (baseline), subjects provided informed consent, completed an online questionnaire consisting of the London Fibromyalgia Epidemiology Study Screening Questionnaire to screen for CWP (bilateral pain above/below waist lasting $\geq 1$ week in the past 3 months), visited a site for physician evaluation for FM, and completed a questionnaire with validated patient-reported outcome instruments. Subjects were classified into mutually exclusive groups: $\mathrm{FM}+\mathrm{CWP}+$ (screened positive for $\mathrm{CWP}$ and received physician diagnosis of FM), FM-CWP+ (screened positive for CWP but did not receive physician diagnosis of FM), and FM-CWP- (screened negative for CWP). Approximately 2 years later (follow-up), subjects were reassessed at the same study site and completed a questionnaire with the same patient-reported outcomes.

Results: Seventy-six FM+CWP+ subjects completed assessments at both time points; $56(73.7 \%)$ met the FM study definition at follow-up. Twenty subjects no longer met the FM study definition (eleven became FM-CWP- and nine became FM-CWP+). Ten subjects (two from $\mathrm{FM}-\mathrm{CWP}-$ and eight from FM-CWP+) transitioned into the $\mathrm{FM}+\mathrm{CWP}+$ group at follow-up; they reported more tender points and pain interference with sleep and worse physical function at baseline compared with subjects who did not transition to FM+CWP+. Most (76.7\%) of the subjects who transitioned into/out of FM+CWP+ experienced changes in CWP, number of positive tender points, or both.

Conclusion: The results suggest that some $\mathrm{FM}+\mathrm{CWP}+$ patients experience fluctuation in symptoms over time, which may reflect the waxing and waning nature of FM and affect diagnosis and treatment.

Keywords: fibromyalgia, chronic widespread pain, physician assessment

\section{Introduction}

Fibromyalgia (FM) is a musculoskeletal pain disorder characterized by chronic widespread pain (CWP), tenderness, stiffness, fatigue, and sleep disturbance. ${ }^{1}$ Patients with FM often also experience headaches, irritable bowel and bladder, anxiety, and depression. $^{2-4}$ There is no specific laboratory test that can be used to diagnose FM, and thus, the only reliable means for diagnosis is physician's assessment. For example, in the study by Arnold et $\mathrm{al}^{1}$ and Bellato et $\mathrm{al},{ }^{5}$ they noted that FM diagnosis is typically 
clinical because laboratory abnormalities are not present. The physician focuses on the signs and symptoms of pain and associated comorbidities. The American College of Rheumatology (ACR) has established criteria to assist with diagnosis. ${ }^{6,7}$

Published FM prevalence estimates vary widely, ${ }^{2,8-16}$ with worldwide estimates ranging from $<1 \%$ (Denmark $)^{8}$ to $10.5 \%$ (Norway, females only). ${ }^{9}$ A previous study in the US estimated $2 \%$ prevalence, while another recent study estimated up to $6.4 \%$ prevalence. ${ }^{2,17}$ Variations in prevalence estimates may be attributed to the study definition of FM, the population studied, and the study-specific methodology.

There is limited information on the symptoms of FM patients over time. Previous research suggests that FM is a chronic condition where symptoms wax and wane over time, ${ }^{18-22}$ though some studies reported that $20 \%-47 \%$ of diagnosed FM patients may no longer meet the study definition of FM at 1-2 years after diagnosis..$^{23,24}$ In a recent US study, $44 \%$ of FM patients did not meet the study definition of FM at some point during the 11-year follow-up. ${ }^{18}$ Longterm studies also suggest that a portion of FM patients may experience improvement in symptoms. ${ }^{18,19,21}$ These studies varied in their assessment methods, either using the results of physician assessment ${ }^{19,21}$ or FM patient survey. ${ }^{18}$

Given the variability in published findings on the progression of FM over time, the aim of this study was to gain a better understanding of the fluctuations of FM in a geographically diverse cohort over a 2 -year time period.

\section{Methods}

Data on the cohort of interest were collected at two points in time, baseline and $\sim 2$ years later at follow-up; the mean time between baseline and follow-up was calculated. A previous publication presented the study methods and findings from the baseline assessment. ${ }^{25}$ In the following, we discuss methods with a focus on follow-up.

\section{Baseline assessment}

The baseline assessment used a multistage approach similar to that used in previous FM studies. ${ }^{2,13}$ At baseline (2011-2012), subjects were recruited from a large, opt-in online panel maintained by Toluna Inc. The panel is composed of $>670,000$ members representing regions across the US, which enabled screening of a large geographically diverse sample. Toluna's panelists are recruited both online and off-line, and no inclusion/exclusion criteria are required to become a registered member of the panel. ${ }^{26}$

Subjects who provided consent were invited to complete a brief online survey to screen for CWP (bilateral pain, above/ below waist lasting $\geq 1$ week in the past 3 months) based on the four pain questions of the six-item London Fibromyalgia Epidemiology Study Screening Questionnaire. ${ }^{27}$ Females were oversampled $(80 \%)$ to mirror the sex distribution of $\mathrm{FM}^{2,13}$ and generate more precision around the estimate of FM.

Physicians at the study site were trained on the manual tender point ${ }^{28}$ and blood pressure cuff examination, ${ }^{29}$ two objective measures, in order to assess the level of FM pain. Physicians also reported treating at least ten FM patients on average each month in their practice. During the site visit, physicians completed an FM assessment, including a tender point examination ${ }^{28}$ and blood pressure cuff examination. ${ }^{29}$ Physicians based the diagnosis of FM on their clinical impression of the subject following the assessment.

After the site visit, subjects completed an online questionnaire that included questions to capture subject demographics, comorbidities, and other clinical characteristics; health care resource utilization; and several validated patient-reported outcome (PRO) instruments. This questionnaire included the Brief Pain Inventory - Short Form (BPI-SF), an 11-item measure to assess pain severity and interference (with function (scored on 0-10 scale with higher scores indicating worse outcomes; Pain Severity Index comprised pain at its worst, least, average, and right now; Pain Interference (with function) Index comprised general activity, mood, walking ability, normal work, relations with other people, sleep, and enjoyment of life $)^{30}$; the modified (self-report) ACR 2010 Criteria, a three-item measure to assess FM symptoms and pain locations (total modified ACR 2010 Criteria scored on 0-31 scale with higher scores indicating worse outcomes) ${ }^{31}$; the Medical Outcomes Study - Sleep Scale, a 12-item measure of sleep outcomes (Overall Sleep Problem Index based on nine items; scored on a 0-100 scale with higher scores indicating more sleep problems) ${ }^{32}$; and the 12-item Short-Form Health Survey, Version 2 (SF-12v2) to assess physical and mental health statuses (scored on a 0-100 scale with higher scores indicating better outcomes; Physical Component Summary and Mental Component Summary scores based on eight domains: physical functioning, role physical, bodily pain, general health, vitality, social functioning, role emotional, and mental health). ${ }^{33}$

\section{Follow-up assessment}

The follow-up assessment (2013-2014) was conducted $\sim 2$ years after the baseline data collection, and subjects who completed the screening survey, site visit, and questionnaire at baseline were eligible to participate for a follow-up assessment. Eligible subjects received an e-mail invitation from Toluna to participate in the follow-up assessment. 
Subjects for whom an e-mail address was no longer in use or a response was not received after five e-mail attempts were called by the study site that performed the subject's baseline evaluation. Study sites made three call attempts, each on separate days at different times, before considering the subject lost to follow-up. Subjects were reassessed for FM by the site physician and completed the London Fibromyalgia Epidemiology Study Screening Questionnaire at the site visit. Subjects then completed an online questionnaire, which included the same PROs as the baseline questionnaire.

Seventeen physicians (five from West, four from Midwest, four from South, and four from Northeast) participated during the follow-up assessment, including nine rheumatologists, two pain specialists, and six primary care physicians. Three sites could not participate at follow-up; subjects who attended one of these three sites at baseline were invited to complete the online subject questionnaire at follow-up but were not assessed by a physician. As they did not have a physician assessment for FM at follow-up, they were excluded from the current analysis.

This observational study received Institutional Review Board (IRB) approval from Quorum Review IRB, Seattle, Washington and Western Institutional Review Board, Olympia, Washington. At baseline and follow-up subjects provided written informed consent. Subjects and sites received compensation commensurate with their time.

\section{Analysis methods}

The analysis consisted of subjects who completed both the baseline and follow-up assessments. Subjects were classified into mutually exclusive groups at each time point (subjects were categorized based on whether they stayed in their baseline group (baseline status $\rightarrow$ follow-up status: FM $\rightarrow$ $\mathrm{FM}, \mathrm{CWP}+\rightarrow \mathrm{CWP}+, \mathrm{CWP}_{-} \rightarrow \mathrm{CWP}-$ ) or transitioned into one of the other groups at follow-up $(\mathrm{FM} \rightarrow \mathrm{CWP}+, \mathrm{FM} \rightarrow$ $\mathrm{CWP}-, \mathrm{CWP}+\rightarrow \mathrm{FM}, \mathrm{CWP}+\rightarrow \mathrm{CWP}-, \mathrm{CWP}-\rightarrow \mathrm{CWP}+$ $\mathrm{CWP}-\rightarrow \mathrm{FM})$ :

- $\mathrm{FM}+\mathrm{CWP}+(\mathrm{CWP}$-positive screen and physicianconfirmed diagnosis of $\mathrm{FM}$ );

- $\mathrm{FM}-\mathrm{CWP}+(\mathrm{CWP}-$ positive screen without physician diagnosis of $F M)$; and

- FM-CWP-(CWP-negative screen).

FM point prevalence and standard errors were estimated at baseline by incorporating sampling weights reflecting the study design (screening and site visit).,13 Additionally, weights reflecting the underlying screened sample (by sex, age, and race) were used in the analysis to adjust the estimates and were implemented using the SURVEYMEANS procedure in SAS. ${ }^{34}$ As females were oversampled, sex-specific estimates were further adjusted by the 2010 Census sex distribution ${ }^{35}$ to provide an overall estimate of prevalence.

At follow-up, subjects who transitioned into or out of the $\mathrm{FM}+\mathrm{CWP}+$ group were identified, and the baseline characteristics of those who transitioned were compared to those who did not transition. Summary statistics were calculated; however, because of the small number of subjects with transitions in their FM status, no tests for statistical significance were performed.

All data were analyzed using SAS Version 9.3 (SAS Institute Inc., Cary, NC, USA).

\section{Results}

\section{Sample characteristics}

At baseline, 8,382 subjects were screened, and 1,939 screened positive for CWP; of the screened subjects, 475 subjects attended a site visit (350 CWP+ and $125 \mathrm{CWP}-$ ), and 174 cases of $\mathrm{FM}+\mathrm{CWP}+$ were identified. ${ }^{25}$ After adjusting with sampling weights, estimated FM prevalence $(95 \%$ confidence interval) was $12.4 \%(11.0,13.8)$ among adult females and $6.4 \%(3.7,9.0)$ among adult males for an overall adjusted FM prevalence estimate for adult females and males of $9.5 \%(7.2,11.7)$. On the basis of a sensitivity analysis, FM diagnosis based on physician clinical impression closely aligned with diagnosis based on both the 1990 ACR criteria and the modified ACR 2010 criteria.

At follow-up, 226 subjects participated: 63 FM-CWP-, $87 \mathrm{FM}-\mathrm{CWP}+$, and $76 \mathrm{FM}+\mathrm{CWP}+$. The mean (SD, range) time from baseline to follow-up assessments was 2.05 ( 0.23 , 1.60-2.57) years. Table 1 presents subject characteristics at follow-up for the sample participating at both time points. No statistically significant changes in subject characteristics were observed over time with the exception of the proportion of subjects with health insurance (from $78.3 \%$ at baseline to $88.1 \%$ at follow-up; $P=0.0003$ ) and prescription drug insurance (from $76.1 \%$ at baseline to $84.4 \%$ at follow-up; $P=0.0009$ ).

Those who participated in both assessments did not differ systematically on demographic and clinical factors, including sex, race, ethnicity, employment status, household income, health insurance and prescription drug coverage, and body mass index, from those who participated at baseline but not in the follow-up assessment.

\section{Diagnostic transitions}

Among the $76 \mathrm{FM}+\mathrm{CWP}+$ subjects who completed the baseline and follow-up assessments, the majority (56 [73.7\%]) still met the study definition of FM at follow-up. Ten subjects 
Table I Characteristics of the follow-up sample

\begin{tabular}{ll}
\hline Characteristic & Follow-up sample \\
\hline Age (years), mean (SD) & $51.7(12.83)$ \\
Female, $\mathrm{n}(\%)$ & $172(78.9)$ \\
Non-Hispanic/Latino, $\mathrm{n}(\%)$ & $210(96.3)$ \\
Body mass index, $\mathrm{n}(\%)$ & \\
$\quad$ Underweight $\left(<18.50 \mathrm{~kg} / \mathrm{m}^{2}\right)$ & $5(2.3)$ \\
$\quad$ Normal $\left(18.50-24.99 \mathrm{~kg} / \mathrm{m}^{2}\right)$ & $58(26.6)$ \\
Overweight $\left(25.00-29.99 \mathrm{~kg} / \mathrm{m}^{2}\right)$ & $55(25.2)$ \\
Obese $\left(\geq 30 \mathrm{~kg} / \mathrm{m}^{2}\right)$ & $100(45.9)$ \\
Employed for pay, $\mathrm{n}(\%)$ & $108(49.5)$ \\
Annual household income, $\mathrm{n}(\%)$ & \\
$<\$ 20,000$ & $50(22.9)$ \\
$\$ 20,000-\$ 44,999$ & $45(20.6)$ \\
$\$ 45,000-\$ 64,999$ & $45(20.6)$ \\
$\$ 65,000-\$ 89,999$ & $40(18.3)$ \\
$\$ 90,000-\$ 124,999$ & $28(12.8)$ \\
$\geq \$ 125,000$ & $10(4.6)$ \\
Health insurance, $\mathrm{n}(\%)$ & $192(88.1)$ \\
Prescription drug insurance, $\mathrm{n}(\%)$ & $184(84.4)$ \\
\hline
\end{tabular}

Note: ${ }^{\mathrm{A} A}$ total of 226 subjects attended a site visit at follow-up, but eight subjects did not complete the subject questionnaire subsequent to the follow-up site visit. Currency shown as US\$.

(two from $\mathrm{FM}-\mathrm{CWP}-$ and eight from $\mathrm{FM}-\mathrm{CWP}+$ ) transitioned into the $\mathrm{FM}+\mathrm{CWP}+$ group (Figure 1). Twenty subjects no longer met the study definition for FM at follow-up and transitioned to the FM-CWP- (eleven) or FM-CWP+ (nine) group (Figure 1). Analysis by site and geographic region did not suggest that the transitions were driven by any particular site(s).

\section{Transitions into FM+CWP+}

The ten subjects who transitioned into the $\mathrm{FM}+\mathrm{CWP}+$ group at follow-up differed from subjects who did not transition to $\mathrm{FM}+\mathrm{CWP}+(\mathrm{ie}$, remained in their respective $\mathrm{FM}-\mathrm{CWP}-$ or

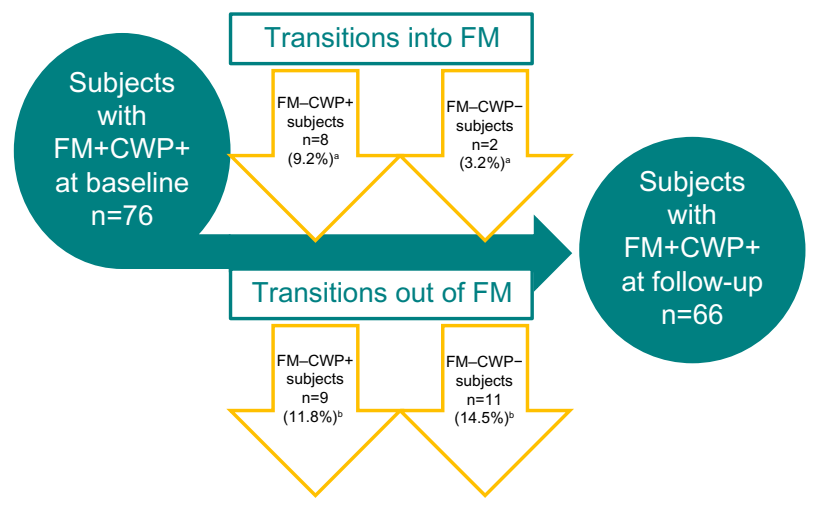

Figure I Fluctuations of FM status: diagnostic transitions.

Notes: ${ }^{a}$ Percentages calculated from among the $87 \mathrm{FM}-\mathrm{CWP}+$ subjects and the 63 FM-CWP- subjects identified at baseline. 'Percentages calculated from among the 76 subjects with $\mathrm{FM}+\mathrm{CWP}+$ at baseline.

Abbreviations: CWP-, chronic widespread pain - negative; CWP+, chronic widespread pain - positive; FM-, not diagnosed with fibromyalgia; FM+, diagnosed with fibromyalgia; FM, fibromyalgia.
$\mathrm{FM}-\mathrm{CWP}+$ group) on some measures. For example, subjects who transitioned from FM-CWP- and FM-CWP+ groups into the FM+CWP+ group at follow-up had higher numbers of tender points on average at baseline compared to subjects who remained in the FM-CWP- and FM-CWP+ groups (Figure 2A). They also had higher modified total ACR 2010 scores (Figure 2B), lower SF-12v2 physical function scores (mean [SD] FM-CWP- $\rightarrow$ FM-CWP-: 87.3 [20.90] vs $\mathrm{FM}-\mathrm{CWP}-\rightarrow \mathrm{FM}+\mathrm{CWP}+: 50.0$ [0.00], FM-CWP+ $\rightarrow$ $\mathrm{FM}-\mathrm{CWP}+: 53.0[31.82]$ vs FM-CWP+ $\rightarrow \mathrm{FM}+\mathrm{CWP}+: 43.8$ [34.72]; Table S1), and greater Brief Pain Inventory - Short Form pain interference with sleep at baseline (mean [SD] FM-CWP- $\rightarrow$ FM-CWP-: 2.1 [2.61] vs FM-CWP- $\rightarrow$ $\mathrm{FM}+\mathrm{CWP}+: 5.0$ [1.41], FM-CWP+ $\rightarrow$ FM-CWP+: 4.2 [3.40] vs FM-CWP+ $\rightarrow$ FM+CWP+: 6.3 [1.98]; Table S1). For other clinical outcomes and PROs, less marked differences were observed among those who transitioned into the FM+CWP+ group at follow-up and those who did not (Table S1).

Half (five [50\%]) of the ten subjects who transitioned into the $\mathrm{FM}+\mathrm{CWP}+$ group experienced an increase in the number of positive tender points $(<11$ to $\geq 11)$ from the baseline to follow-up assessment. Both subjects who transitioned from $\mathrm{FM}-\mathrm{CWP}-$ to $\mathrm{FM}+\mathrm{CWP}+$ did not meet the study definition for FM at baseline (which required positive screen for CWP and physician diagnosis), although they were diagnosed with FM by the physician at both time points.

Among the ten subjects who transitioned into $\mathrm{FM}+\mathrm{CWP}+$ at follow-up, the following comorbidities were reported at baseline: anxiety $(\mathrm{n}=2)$, arthritis $(\mathrm{n}=6)$, depressive symptoms $(\mathrm{n}=5)$, diabetes $(\mathrm{n}=1)$, headache/migraine $(\mathrm{n}=4)$, hypertension $(n=1)$, irritable bowel syndrome (IBS; $n=2)$, lower back pain $(n=6)$, and sleep apnea $(n=1)$. Nine of the ten subjects who transitioned into the $\mathrm{FM}+\mathrm{CWP}+$ group reported changes in the presence of 12 different comorbidities from the baseline to the follow-up assessment. These changes included new comorbidities (ie, anxiety [n=1], arthritis [n=1], chronic fatigue syndrome $[\mathrm{n}=2]$, headache/migraine $[\mathrm{n}=1]$, hypertension $[\mathrm{n}=1]$, lower back pain [ $n=1]$, restless leg syndrome [RLS; $n=1]$, sleep apnea $[\mathrm{n}=1]$, and temporomandibular joint disorder [TMJD; $\mathrm{n}=1]$ ) as well as comorbidities that were no longer reported at follow-up (ie, anxiety [ $\mathrm{n}=1]$, arthritis [n=2], depressive symptoms [n=3], diabetes $[n=1]$, headache/migraine $[n=2]$, IBS $[n=1]$, lower back pain [ $\mathrm{n}=4]$, and sleep apnea $[\mathrm{n}=1])$.

The ten subjects who transitioned into the $\mathrm{FM}+\mathrm{CWP}+$ group at follow-up reported using the following prescription medication classes for pain and/or FM in the 3 months prior to the baseline assessment: antiepileptics $(n=1)$, muscle 

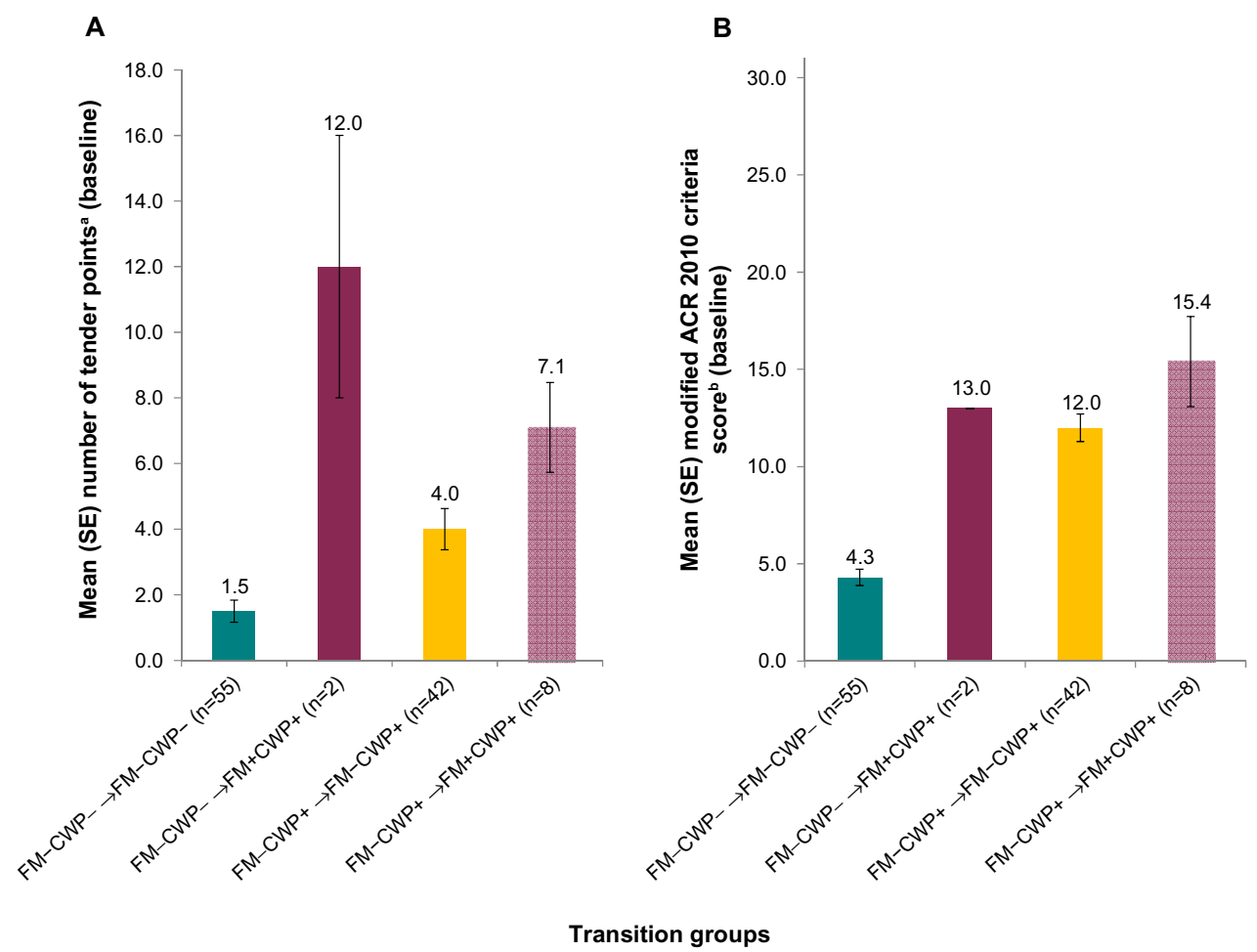

Figure 2 Comparison of transition groups: subjects who transitioned into the FM+CWP+ group versus subjects who remained in the FM-CWP- and FM-CWP+ groups at follow-up.

Notes: (A) Mean (SE) number of tender points at baseline. (B) Mean (SE) modified ACR 2010 criteria score at baseline. ${ }^{a}$ Range: $0-18$, with higher number indicating more areas of pain and tenderness. ${ }^{\circ}$ Range: $0-3 \mathrm{l}$, with higher scores indicating more FM symptoms/worse outcomes. For FM-CWP- $\rightarrow$ FM+CWP+, the subjects had the same scores, and hence, there is no variability/error bars.

Abbreviations: ACR, American College of Rheumatology; CWP+, chronic widespread pain -positive; CWP-, chronic widespread pain - negative; FM+, diagnosed with fibromyalgia; FM-, not diagnosed with fibromyalgia; SE, standard error.

relaxants $(\mathrm{n}=2)$, nonsteroidal anti-inflammatory drugs $(\mathrm{n}=1)$, strong short-acting opioids $(\mathrm{n}=1)$, weak short-acting opioids $(\mathrm{n}=2)$, tetracyclic and miscellaneous antidepressants $(\mathrm{n}=2)$, tricyclic antidepressants $(n=1)$, tramadol $(n=1)$, and "other" prescription medications $(n=3)$. Eight of the ten subjects who transitioned into the $\mathrm{FM}+\mathrm{CWP}+$ group reported changes in the use of seven specific prescription medication classes and in the "other" prescription medication category from the baseline to the follow-up assessment. These changes reflect new medication classes that subjects started taking prior to follow-up as well as medication classes that subjects stopped taking after the baseline assessment (Figure 3). The remaining two subjects who transitioned into the $\mathrm{FM}+\mathrm{CWP}+$ group reported taking "other" prescription medications at both time points; one of the subjects also reported taking nonsteroidal anti-inflammatory drugs at both time points.

Among the ten subjects who transitioned into the $\mathrm{FM}+\mathrm{CWP}+$ group at follow-up, five (one $\mathrm{FM}-\mathrm{CWP}-\rightarrow$ $\mathrm{FM}+\mathrm{CWP}+$ and four $\mathrm{FM}-\mathrm{CWP}+\rightarrow \mathrm{FM}+\mathrm{CWP}+$ ) reported one or more pain-related health care provider visits (mean [SD]: FM-CWP- $\rightarrow$ FM+CWP+: 1.0 [NA]; FM-CWP+ $\rightarrow \mathrm{FM}+\mathrm{CWP}+: 5.0$ [5.42]) in the 3 months before the baseline assessment. Nine subjects who transitioned into the FM group at follow-up (one FM-CWP- $\rightarrow$ FM+CWP+ and eight $\mathrm{FM}-\mathrm{CWP}+\rightarrow \mathrm{FM}+\mathrm{CWP}+$ ) reported taking nonprescription medications for pain in the 3 months prior to the baseline assessment. Two subjects who transitioned into the $\mathrm{FM}+\mathrm{CWP}+$ group at follow-up (one $\mathrm{FM}-\mathrm{CWP}-\rightarrow$ $\mathrm{FM}+\mathrm{CWP}+$, one $\mathrm{FM}-\mathrm{CWP}+\rightarrow \mathrm{FM}+\mathrm{CWP}+$ ) reported using physical treatments for pain in the 3 months prior to the baseline assessment.

\section{Transitions out of FM+CWP+}

The 20 subjects who no longer met the study definition and transitioned out of the $\mathrm{FM}+\mathrm{CWP}+$ group at follow-up differed from subjects who remained in the $\mathrm{FM}+\mathrm{CWP}+$ group on some baseline measures. Specifically, subjects who transitioned out of the $\mathrm{FM}+\mathrm{CWP}+$ group had been diagnosed with FM more recently (mean [SD] number of months since diagnosis; FM+CWP+ $\rightarrow$ FM-CWP-: 2.4 [7.52], $\mathrm{FM}+\mathrm{CWP}+\rightarrow \mathrm{FM}-\mathrm{CWP}+: 15.6$ [46.81] vs $\mathrm{FM}+\mathrm{CWP}+$ $\rightarrow$ FM+CWP+: 64.0 [92.30]; Table S2) and reported higher baseline SF-12v2 physical function scores $(\mathrm{FM}+\mathrm{CWP}+$ $\rightarrow$ FM-CWP-: 40.9 [30.15], FM+CWP+ $\rightarrow$ FM-CWP+: 


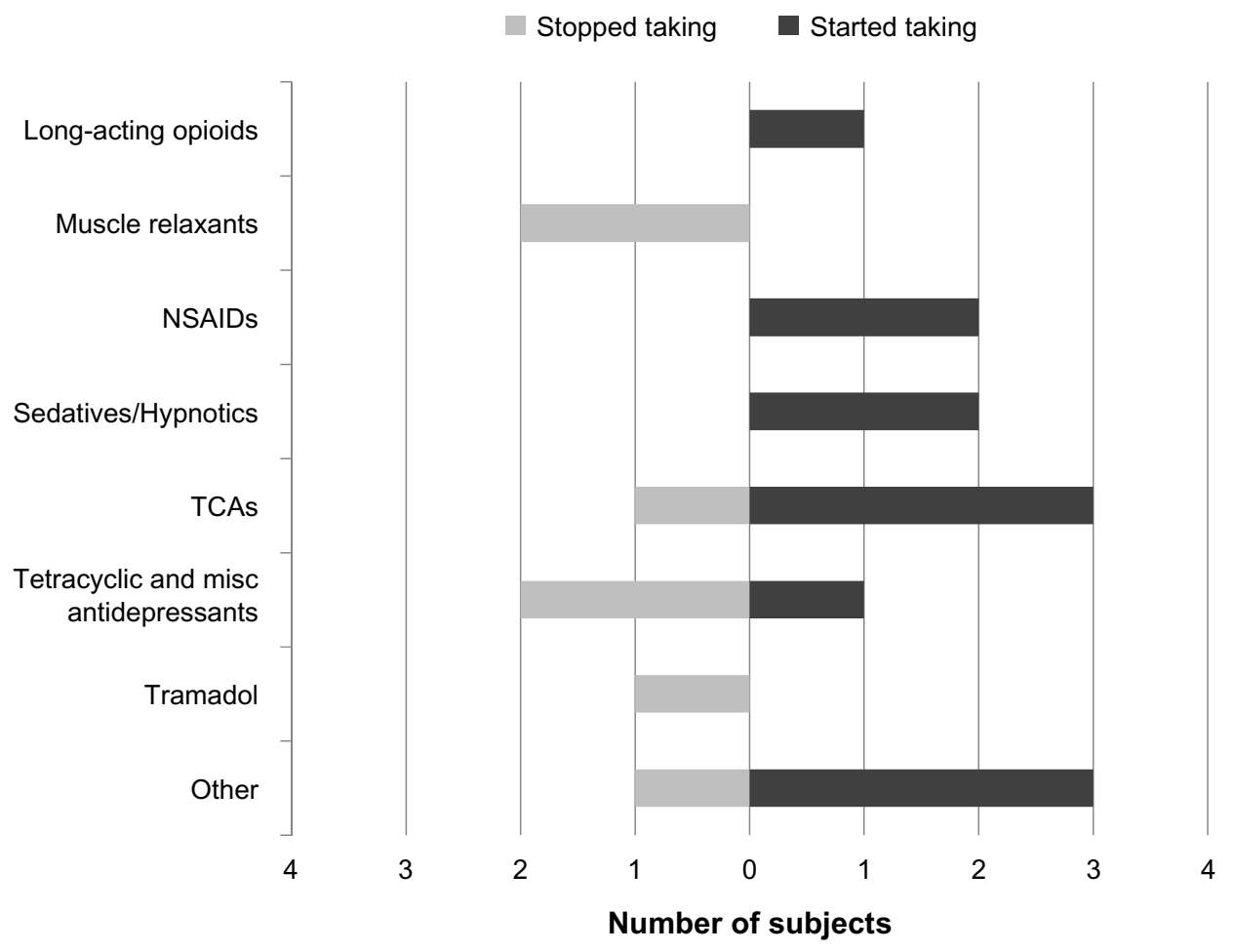

Figure 3 Prescription medication classes started and stopped since baseline assessment among new FM+CWP+ cases.

Abbreviations: CWP+, chronic widespread pain - positive; FM+, diagnosed with fibromyalgia; misc, miscellaneous; NSAID, nonsteroidal anti-inflammatory drug; TCA, tricyclic antidepressant.

47.2 [34.11] vs FM+CWP+ $\rightarrow$ FM+CWP+: 29.9 [31.41]; Table S2) and higher baseline SF-12v2 bodily pain scores/ less bodily pain (FM+CWP+ $\rightarrow$ FM-CWP-: 52.3 [20.78], $\mathrm{FM}+\mathrm{CWP}+\rightarrow \mathrm{FM}-\mathrm{CWP}+: 50.0$ [27.95] vs FM+CWP+ $\rightarrow$ FM+CWP+: 36.6 [23.82]; Table S2). For other clinical outcomes and PROs, less marked differences were observed among those who transitioned out of the FM+CWP+ group at follow-up and those who remained in the $\mathrm{FM}+\mathrm{CWP}+$ group (Table S2).

Thirty percent of subjects ( six out of 20) who transitioned out of the $\mathrm{FM}+\mathrm{CWP}+$ group at follow-up experienced a reduction in the number of positive tender points $(\geq 11$ to $<11$ ) between assessments. Eleven subjects were CWP- at follow-up; eight of these subjects, though the physician confirmed FM at both assessments, did not meet the FM study definition because they screened negative for CWP at follow-up.

Among the 20 subjects who transitioned out of the $\mathrm{FM}+\mathrm{CWP}+$ group at follow-up, the following comorbidities were reported at baseline: anxiety $(n=5)$, arthritis $(n=8)$, chronic fatigue syndrome $(n=3)$, depressive symptoms $(n=9)$, diabetes $(n=6)$, headache/migraine $(n=4)$, hypertension $(n=8)$, IBS $(n=3)$, lower back pain $(n=10)$, neuropathies $(n=1)$, RLS $(n=2)$, sleep apnea $(n=5)$, and TMJD $(n=3)$. Sixteen of the
20 subjects who transitioned out of the $\mathrm{FM}+\mathrm{CWP}+$ group reported changes in the presence of 12 different comorbidities from the baseline to the follow-up assessment. These changes included new comorbidities (ie, chronic fatigue syndrome $[n=1]$, headache/migraine $[n=1]$, hypertension $[n=1]$, lower back pain [n=4], neuropathies [n=2], and sleep apnea $[\mathrm{n}=1]$ ) as well as comorbidities no longer reported at follow-up (ie, anxiety $[\mathrm{n}=1]$, arthritis $[\mathrm{n}=1]$, depressive symptoms $[\mathrm{n}=1]$, diabetes $[n=2]$, headache/migraine $[n=1]$, hypertension $[n=3]$, lower back pain [n=3], RLS [n=2], sleep apnea [n=1], and TMJD [n=1]).

The 20 subjects who transitioned out of the FM+CWP+ group at follow-up reported using the following classes of prescription medication for pain and/or FM at baseline: strong short-acting opioids $(\mathrm{n}=2)$, selective serotonin reuptake inhibitors $(n=1)$, benzodiazepines $(n=1)$, tramadol $(n=1)$, and "other" prescription medications $(n=4)$. Fifteen of the 20 subjects who transitioned out of the FM+CWP+ group reported changes in the use of six specific prescription medication classes and in the "other" prescription medication category from the baseline to the follow-up assessment. These changes reflect new medication classes that subjects started taking prior to follow-up as well as medication classes that subjects stopped taking after the baseline assessment 


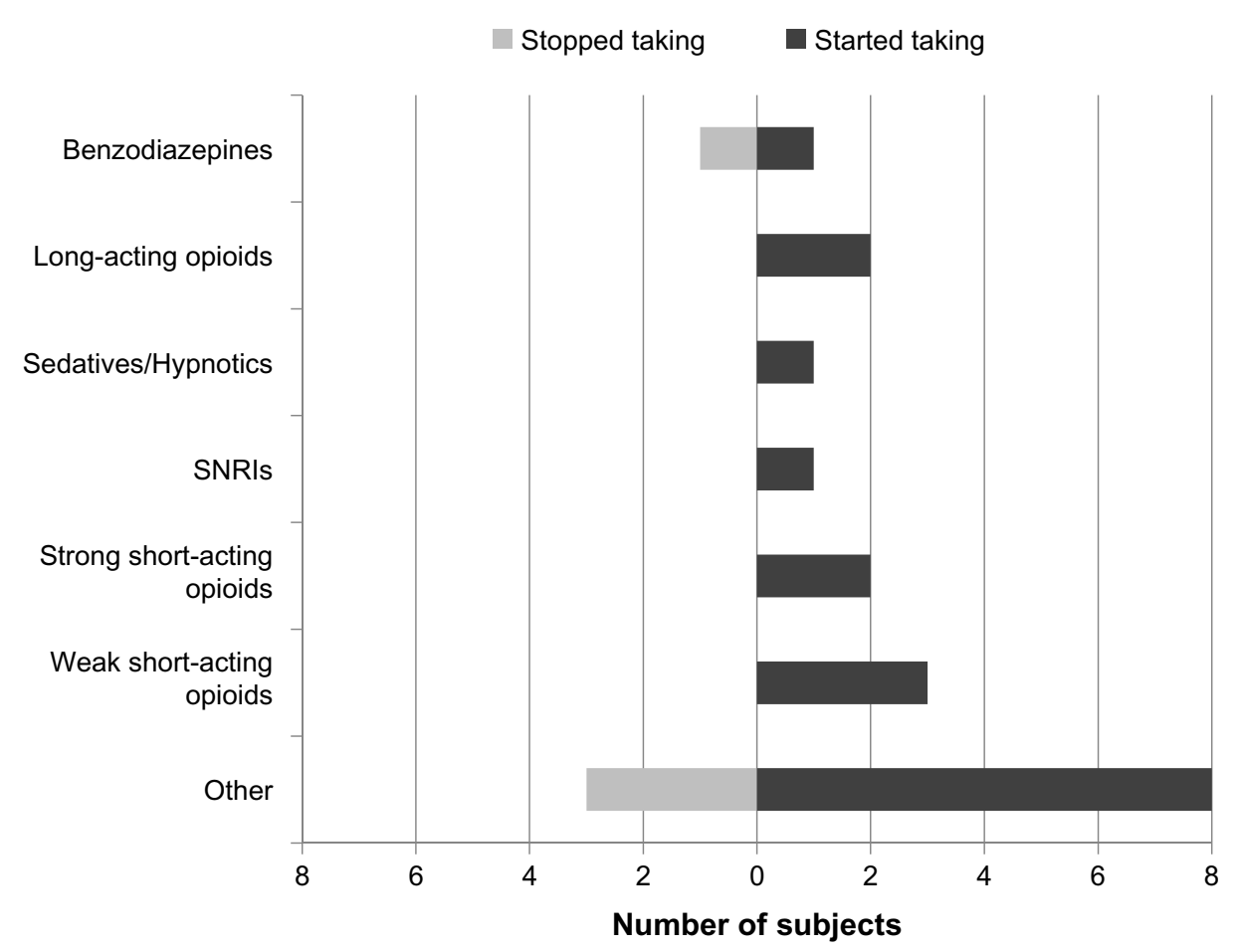

Figure 4 Prescription medication classes started and stopped since baseline assessment among subjects who transitioned out of the FM+CWP+ group. Abbreviations: CWP+, chronic widespread pain - positive; FM+, diagnosed with fibromyalgia; SNRI, selective norepinephrine reuptake inhibitor.

(Figure 4). Among the remaining five subjects who transitioned out of the FM+CWP+ group at follow-up, two did not report prescription medication use at either time point, one reported taking tramadol at baseline and follow-up, one reported taking selective serotonin reuptake inhibitors at baseline and follow-up, and one reported taking "other" prescription medications at baseline and follow-up.

Among the 20 subjects who transitioned out of the $\mathrm{FM}+\mathrm{CWP}+$ group at follow-up, ten (six $\mathrm{FM}+\mathrm{CWP}+\rightarrow$ $\mathrm{FM}-\mathrm{CWP}-$ and four $\mathrm{FM}+\mathrm{CWP}+\rightarrow \mathrm{FM}-\mathrm{CWP}+$ ) reported one or more pain-related health care provider visits (mean [SD] FM+CWP+ $\rightarrow$ FM-CWP-: 3.8 [2.93]; FM+CWP $\rightarrow$ FM-CWP+: 3.8 [3.40]) in the 3 months before the baseline assessment. A majority of the subjects who remained in the $\mathrm{FM}+\mathrm{CWP}+$ group at follow-up $(40 / 56,71.4 \%)$ reported one or more health care provider visits (mean [SD] FM+CWP+ $\rightarrow \mathrm{FM}+\mathrm{CWP}+\mathrm{s} .9$ [6.39]). Eighteen of the 20 subjects who transitioned out of the FM+CWP+ group at follow-up (90\%; nine $\mathrm{FM}+\mathrm{CWP}+\rightarrow \mathrm{FM}-\mathrm{CWP}-$ and nine $\mathrm{FM}+\mathrm{CWP}+\rightarrow$ FM-CWP+) and 46 of the $56(82.1 \%)$ subjects who remained in the $\mathrm{FM}+\mathrm{CWP}+$ group reported taking nonprescription medications for pain in the 3 months prior to the baseline assessment. Four of the 20 subjects who transitioned out of the $\mathrm{FM}+\mathrm{CWP}+$ group at follow-up $(20 \%$; two $\mathrm{FM}+\mathrm{CWP}+\rightarrow$ $\mathrm{FM}-\mathrm{CWP}-$, two $\mathrm{FM}+\mathrm{CWP}+\rightarrow \mathrm{FM}-\mathrm{CWP}+$ ) and 18 of the
56 subjects $(32.1 \%)$ who remained in the $\mathrm{FM}+\mathrm{CWP}+$ group reported using physical treatments for pain in the 3 months prior to the baseline assessment.

\section{Discussion}

Our results support previous research, which suggests that while FM is a chronic illness, there may be waxing and waning of symptoms, as well as a portion of subjects who experience improvements following diagnosis and treatment. The majority of FM+CWP+ patients at baseline (73.7\%) were also CWP+ patients and were rediagnosed by the physician at follow-up. Therefore, the FM population in our study was generally stable over the 2-year period.

At the follow-up assessment, ten subjects who did not have FM at baseline met the study definition of FM. Data from these ten subjects suggested that high number of tender points and modified ACR 2010 criteria scores, and suboptimal physical function and pain interference with sleep outcomes may be present in patients who develop FM. These findings add to the findings of Bergman et $\mathrm{al}^{36}$ that the number of painful regions among individuals with no chronic pain and chronic regional pain at baseline was the strongest predictor of the development of CWP at the 3-year follow-up. That said, these findings are preliminary, and future research on predictors of CWP and FM is needed. 
In one previous study, patient-reported improvements since diagnosis were correlated with younger age and shorter duration of FM symptoms at diagnosis. ${ }^{19}$ Prior research has suggested a link between the duration of exposure to FM pain symptoms and the amount of gray matter loss and rostral anterior cingulate cortex atrophy, respectively. ${ }^{37,38}$ In the current study, $26.3 \%$ of FM+CWP+ subjects identified at the baseline assessment no longer met the study definition at follow-up, and those who transitioned out of the $\mathrm{FM}+\mathrm{CWP}+$ group at follow-up had been more recently diagnosed at baseline than those who did not transition out of the FM+CWP+ group. A study conducted in London, Ontario, reported results comparable to those in the current study: $20 \%$ of the London population sample no longer met the study definition of FM 18 months after initial diagnosis. ${ }^{39}$ In an earlier 2-year prospective study of FM subjects, $47 \%$ of FM patients no longer met ACR criteria, and "remission of FM was objectively identified" in $24 \%$ of the sample. ${ }^{24}$ The results of published studies and the current findings suggest that some FM patients may experience short- or long-term remission of FM symptoms. The concept that FM is part of a larger continuum of central pain disorders identified as "central sensitivity syndromes" may play a part in symptom variation..$^{40}$

Of the patients in our study who no longer met the study definition of FM, only one patient stopped taking a medication class; the majority of changes in medication use between assessments were the initiation of new medication classes. This could suggest that initiation of new medications may have contributed to symptom relief and some subjects no longer meeting study definition for FM. Proactive management (both pharmacologic and nonpharmacologic) in the first years after diagnosis could influence long-term outcomes in some FM patients, though additional research on this topic is needed.

\section{Strengths and limitations}

Strengths of the current study include the geographically diverse study sites and sample, the in-person evaluation by the same site at baseline and follow-up, and administration of the same validated PRO measures at both assessments, which allowed for an assessment of the characteristics of the transition groups. The findings point to the value of PRO measures, among many other diagnostic and clinical tools, in helping clinicians identify patients at risk of developing FM. In addition to the data on FM subjects, the study provides data on the transitions into and out of the FM+CWP+ group. However, due to the small sample sizes in each of the transition status groups, the presented results are descriptive and not inferential.

As a result of the requirements of the Institutional Review Board to disclose the purpose of the study in the email invitation and informed consent, the response at baseline may have been higher among those with chronic pain, FM, or both, despite language in the informed consent designed to encourage participation of those without chronic pain. Although the overall estimated FM prevalence was higher than some previous estimates, the characteristics of our FM sample were similar to other FM samples in the literature. , 17,41,42 $^{2}$

Participants were contacted with an invitation to participate in a follow-up assessment just prior to follow-up data collection. As such, additional contact information was not collected at baseline, which limited our ability to recontact some of the subjects at follow-up. While comparable loss to follow-up has been reported in previous studies, ${ }^{43-45}$ some other studies have reported higher follow-through. ${ }^{20,46}$

Finally, for the most part, subjects were not treated by the study sites between baseline and follow-up assessments; physicians made FM diagnoses at baseline and follow-up based on their examination of the subjects without detailed knowledge of the patient's medical history or previous and current therapies.

\section{Conclusion}

In this descriptive observational study of FM-CWP-, $\mathrm{FM}-\mathrm{CWP}+$, and $\mathrm{FM}+\mathrm{CWP}+$ subjects, the majority of subjects remained in the same group classification at both assessment points. For FM-CWP- and FM-CWP+ subjects, marked pain and suboptimal physical function and pain interference with sleep may signal a transition to $\mathrm{FM}+\mathrm{CWP}+$. For $\mathrm{FM}+\mathrm{CWP}+$ subjects, recent diagnosis, along with less severe pain and better physical function, may be associated with an improvement in FM. The results suggest that some patients may experience fluctuation in symptoms, such as pain, physical function, and sleep over time, which may reflect the waxing and waning nature of FM. These findings suggest a need for further research to better understand the type of patients who transition into or out of the $\mathrm{FM}+\mathrm{CWP}+$ group.

\section{Acknowledgments}

This research was sponsored by Pfizer Inc. We would like to thank Ms Arthi B Chandran, Dr Annlouise Assaf, and Dr Gergana Zlateva for their contributions to the study design and implementation in the baseline assessment; Ms Rebecca Baik, an employee of Covance Market Access Services Inc, for her programming support throughout the data analysis; 
and the study investigators for their contributions to the study execution.

\section{Disclosure}

This study was sponsored by Pfizer Inc. Ms Margarita Udall, Ms Elizabeth Masters, Dr Joseph Cappelleri, Dr Andrew Clair, and Ms Markay Hopps are employees of Pfizer Inc. Ms Heather McElroy, Ms Rachael Mann, Ms Caroline Schaefer, and Dr Shoshana Daniel are employees of Covance Market Access Services Inc, which was paid by Pfizer for study design, execution, analysis, and manuscript development. Dr Edgar Adams was an employee of Covance Market Access Services Inc at the time of the study and manuscript development, and is now retired. Dr Philip Mease, Dr Stuart Silverman, and Dr Roland Staud were investigators for the study. They were not financially compensated for collaborative efforts on publication-related activities. The authors report no other conflicts of interest in this work.

\section{References}

1. Arnold LM, Clauw DJ, Dunegan LJ, Turk DC; FibroCollaborative. A framework for fibromyalgia management for primary care providers. Mayo Clin Proc. 2012;87:488-496.

2. Wolfe F, Ross K, Anderson J, Russell I, Hebert L. The prevalence and characteristics of fibromyalgia in the general population. Arthritis Rheum. 1995;38:19-28.

3. Schaefer C, Chandran A, Hufstader M, et al. The comparative burden of mild, moderate and severe fibromyalgia: results from a crosssectional survey in the United States. Health Qual Life Outcomes. 2011;9:71-83.

4. Bennett RM, Jones J, Turk DC, Russell IJ, Matallana L. An internet survey of 2,596 people with fibromyalgia. BMC Musculoskelet Disord. 2007;8:27-37.

5. Bellato E, Marini E, Castoldi F, et al. Fibromyalgia syndrome: etiology, pathogenesis, diagnosis, and treatment. Pain Res Treat. 2012;2012:426130.

6. Wolfe F, Clauw D, Fitzcharles M, et al. The American College of Rheumatology preliminary diagnostic criteria for fibromyalgia and measurement of symptom severity. Arthritis Care Res. 2010;62: 600-610.

7. Wolfe F, Smythe H, Yunus M, et al. The American College of Rheumatology criteria for the classification of fibromyalgia: report of the multicenter criteria committee. Arthritis Rheum. 1990;30:160-173.

8. Prescott E, Kjøller M, Jacobsen S, Bülow PM, Danneskiold-Samsøe B, Kamper-Jørgensen F. Fibromyalgia in the adult Danish population: a prevalence study. Scand J Rheumatol. 1993;22:233-237.

9. Forseth K, Gran JT. The prevalence of fibromyalgia among women aged 20-49 years in Arendal, Norway. Scand J Rheumatol. 1992; 21:74-78.

10. Wolfe F, Brähler E, Hinz A, Häuser W. Fibromyalgia prevalence, somatic symptom reporting, and the dimensionality of polysymptomatic distress: results from a survey of the general population. Arthritis Care Res (Hoboken). 2013;65:777-785.

11. Branco JC, Bannwarth B, Failde I, et al. Prevalence of fibromyalgia: a survey in five European countries. Semin Arthritis Rheum. 2010;39: 448-453.

12. Carmona L, Ballina J, Gabriel R, Laffon A; EPISER Study Group. The burden of musculoskeletal diseases in the general population of Spain: results from a national survey. Ann Rheum Dis. 2001;60:1040-1045.
13. White KP, Speechley M, Harth M, Ostbye T. The London Fibromyalgia Epidemiology Study: the prevalence of fibromyalgia syndrome in London, Ontario. J Rheumatol. 1999;26:1570-1576.

14. Mas A, Carmona L, Valverde M, Ribas B; EPISER Study Group. Prevalence and impact of fibromyalgia on function and quality of life in individuals in the general population: results from a nationwide study in Spain. Clin Exp Rheumatol. 2008;26:519-526.

15. Neumann L, Buskila D. Epidemiology of fibromyalgia. Curr Pain Headache Rep. 2003;7:362-368.

16. Jones GT, Atzeni F, Beasley M, Flüß E, Sarzi-Puttini P, Macfarlane GJ. The prevalence of fibromyalgia in the general population - a comparison of the American College of Rheumatology 1990, 2010 and modified 2010 classification criteria. Arthritis Rheum. 2015;67:568-575.

17. Vincent A, Lahr BD, Wolfe F, et al. Prevalence of fibromyalgia: a population-based study in Olmsted County, Minnesota, utilizing the Rochester Epidemiology Project. Arthritis Care Res. 2013;65: 786-792.

18. Walitt B, Fitzcharles MA, Hassett AL, Katz RS, Hauser W, Wolfe F. The longitudinal outcome of fibromyalgia: a study of 1555 patients. J Rheumatol. 2011;38:2238-2246.

19. Kennedy M, Felson D. A prospective long-term study of fibromyalgia syndrome. Arthritis Rheum. 1996;39:682-685.

20. Forseth K, Forre O, Gran J. A 5.5 year prospective study of self-reported musculoskeletal pain and of fibromyalgia in a female population: significance and natural history. Clin Rheumatol. 1999;18:114-121.

21. Ledingham J, Doherty S, Doherty M. Primary fibromyalgia syndrome-an outcome study. Br J Rheumatol. 1993;32:139-142.

22. Bengtsson A, Backman E, Lindblom B, Skogh T. Long-term follow up of fibromyalgia patients: clinical symptoms, muscular function, laboratory tests-an eight year comparison study. J Musculoskelet Pain. 1994;2(2):67-80.

23. White K, Harth M. Classification, epidemiology, and natural history of fibromyalgia. Curr Pain Headache Rep. 2001;5:320-329.

24. Granges G, Zilko P, Littlejohn G. Fibromyalgia syndrome: assessment of the severity of the condition 2 years after diagnosis. J Rheumatol. 1994;21:523-529.

25. Schaefer C, Mann R, Masters ET, et al. The comparative burden of chronic widespread pain and fibromyalgia in the United States. Pain Pract. Epub 2015 May 16.

26. Toluna USA, Inc [homepage on the Internet]. Available from: http:// www.toluna-group.com/. Accessed January 24, 2014.

27. White K, Harth M, Speechley M, Ostbye T. Testing an instrument to screen for fibromyalgia syndrome in general population studies: the London Fibromyalgia Epidemiology Study Screening Questionnaire. J Rheumatol. 1999;26:880-884.

28. Sinclair J, Starz TW, Turk D. The Manual Tender Point Survey. Pittsburgh, PA: University of Pittsburgh Medical Center, Center for Continuing Education in the Health Sciences; 1997.

29. Vargas A, Hernandez-Paz R, Sanchez-Huerta JM, et al. Sphygmomanometry-evoked allodynia - a simple bedside test indicative of fibromyalgia: a multicenter developmental study. J Clin Rheumatol. 2006;12(6):272-274.

30. Cleeland $\mathrm{C}$ [webpage on the Internet]. The Brief Pain Inventory User Guide. 2008. Available from: http://www.mdanderson.org/ education-and-research/departments-programs-and-labs/departmentsand-divisions/symptom-research/symptom-assessment-tools/BPI_ UserGuide.pdf. Accessed July 05, 2011.

31. Wolfe F, Clauw DJ, Fitzcharles MA, et al. Fibromyalgia criteria and severity scales for clinical and epidemiological studies: a modification of the ACR preliminary diagnostic criteria for fibromyalgia. J Rheumatol. 2011;38(6):1113-1122.

32. Hays R, Stewartm A. Sleep Measures. Measuring Functioning and Well-being: The Medical Outcomes Study Approach. Durham, NC: Duke University Press; 1992.

33. Ware J, Kosinski M, Keller S. A 12-Item Short-Form Health Survey: construction of scales and preliminary tests of reliability and validity. Med Care. 1996;34(3):220-233. 
34. Baxter A, Huddleston E, editors. SAS Institute Inc. Chapter 99 the SURVEYMEANS procedure. SAS/STAT 13.2 User's Guide. Cary, NC: SAS Institute Inc; 2014:8154-8238.

35. U.S. Census Bureau [webpage on the Internet]. 2010 Census Briefs. 2012. Available from: http://www.census.gov/2010census/data/2010census-briefs.php. Accessed June 26, 2012.

36. Bergman S, Herrström P, Jacobsson LT, Petersson IF. Chronic widespread pain: a three year followup of pain distribution and risk factors. J Rheumatol. 2002;29:818-825.

37. Jensen KB, Srinivasan P, Spaeth R, et al. Overlapping structural and functional brain changes in patients with long-term exposure to fibromyalgia pain. Arthritis Rheum. 2013;65(12):3293-3303.

38. Kuchinad A, Schweinhardt P, Seminowicz DA, Wood PB, Chizh BA, Bushnell MC. Accelerated brain gray matter loss in fibromyalgia patients: premature aging of the brain? J Neurosci. 2007;27(15): 4004-4007.

39. White K, Speechley M, Harth M, Østbye T. Remission rate in fibromyalgia syndrome (FMS). Paper presented at: XII Pan-American Congress of Rheumatology; June 21-25, 1998; Montreal, QC.

40. Phillips K, Clauw DJ. Central pain mechanisms in chronic pain states - maybe it is all in their head. Best Pract Res Clin Rheumatol. 2011;25(2):141-154.
41. Wolfe F, Goldenberg DL, Walitt BT, Häuser W. The Polysymptomatic Distress Scale as a measure of disease and practice severity in fibromyalgia. Oral Presentation at the American College of Rheumatology Annual Meeting; 2013; San Diego, CA.

42. Kim CH, Luedtke CA, Vincent A, Thompson JM, Oh TH. Association of body mass index with symptom severity and quality of life in patients with fibromyalgia. Arthritis Care Res (Hoboken). 2012;64:222-228.

43. Nöller V, Sprott H. Prospective epidemiological observations on the course of the disease in fibromyalgia patients. J Negat Results Biomed. 2003;2:4-9.

44. Gupta A, Silman AJ, Ray D, et al. The role of psychosocial factors in predicting the onset of chronic widespread pain: results from a prospective population-based study. Rheumatology. 2007;46:666-671.

45. Mundal I, Gråwe RW, Bjørngaard JH, Linaker OM, Fors EA. Prevalence and long-term predictors of persistent chronic widespread pain in the general population in an 11-year prospective study: the HUNT study. BMC Musculoskelet Disord. 2014;15:213-224.

46. Fitzcharles MA, Faregh N, Ste-Marie PA, Shir Y. Opioid use in fibromyalgia is associated with negative health related measures in a prospective cohort study. Pain Res Treat. 2013;2013:898493. 


\section{Supplementary materials}

Table SI Comparison of clinical and patient-reported outcomes at baseline: subjects who transitioned into the FM+CWP+ group versus subjects who remained in the FM-CWP- and FM-CWP+ groups at follow-up

\begin{tabular}{|c|c|c|c|c|}
\hline Outcome, mean (SD) & $\begin{array}{l}\text { FM-CWP- } \rightarrow \\
\text { FM-CWP- }(n=55)\end{array}$ & $\begin{array}{l}\text { FM-CWP- } \rightarrow \\
\text { FM+CWP+ }(n=2)\end{array}$ & $\begin{array}{l}\text { FM-CWP+ } \rightarrow \\
\text { FM-CWP+ }(n=42)\end{array}$ & $\begin{array}{l}\text { FM-CWP+ } \rightarrow \\
\text { FM+CWP+ }(n=8)\end{array}$ \\
\hline Number of comorbidities & I.I (I.I8) & $2.0(I .4 I)$ & $3.1(1.92)$ & $3.9(1.89)$ \\
\hline Among those with $\geq I^{a}$ & $1.9(0.91)$ & $2.0(I .4 I)$ & $3.3(1.83)$ & $3.9(1.89)$ \\
\hline BPI-SF Pain Severity Index ${ }^{\mathrm{b}, \mathrm{c}}$ & $2.5(2.16)$ & $2.9(0.18)$ & $4.2(1.96)$ & $4.6(1.40)$ \\
\hline Pain at worst, past 24 hours & $3.4(2.52)$ & $3.0(I .4 I)$ & $5.4(2.34)$ & $6.0(2.00)$ \\
\hline Pain at least, past 24 hours & $1.5(2.14)$ & $2.5(0.7 \mathrm{I})$ & $2.8(2.19)$ & $3.0(1.20)$ \\
\hline Average pain & $3.2(2.43)$ & $3.0(0.00)^{\mathrm{d}}$ & $4.5(1.84)$ & $4.9(1.13)$ \\
\hline Pain right now & $1.8(2.38)$ & $3.0(0.00)^{d}$ & $4.2(2.39)$ & $4.5(1.85)$ \\
\hline BPI-SF Pain Interference Index $x^{\mathrm{b}, \mathrm{c}}$ & $1.8(2.33)$ & $2.6(0.7 I)$ & $4.0(2.65)$ & $5.3(1.80)$ \\
\hline General activity & $1.9(2.6 \mathrm{I})$ & $2.5(0.7 \mathrm{I})$ & $4.2(2.90)$ & $5.0(1.93)$ \\
\hline Mood & $2.1(2.7 I)$ & $2.0(I .4 I)$ & $3.6(3.02)$ & $6.3(2.82)$ \\
\hline Walking ability & $1.6(2.42)$ & $2.0(0.00)$ & $4.2(3.08)$ & $4.4(2.72)$ \\
\hline Normal work & $1.7(2.69)$ & $2.5(0.7 \mathrm{I})$ & $4.3(3.01)$ & $5.0(2.07)$ \\
\hline Relations with other people & I.I (2.19) & $1.0(I .4 I)$ & $2.9(2.97)$ & $4.4(3.16)$ \\
\hline Sleep & $2.1(2.6 \mathrm{I})$ & $5.0(I .4 I)$ & $4.2(3.40)$ & $6.3(1.98)$ \\
\hline Enjoyment of life & $2.0(2.75)$ & $3.5(2.12)$ & $4.5(3.22)$ & $5.9(2.85)$ \\
\hline MOS-SS Overall Sleep Problem Index & $27.2(16.44)$ & $42.2(4.7 I)$ & $43.3(16.25)$ & $54.0(16.00)$ \\
\hline \multicolumn{5}{|l|}{$S F-12 v 2^{e}$} \\
\hline Physical Component Summary & $51.9(7.45)$ & $42.7(3.56)$ & $38.8(10.96)$ & $36.6(8.47)$ \\
\hline Mental Component Summary & $51.7(8.82)$ & $48.1(7.89)$ & $45.6(12.52)$ & $45.9(10.85)$ \\
\hline Physical function & $87.3(20.90)$ & $50.0(0.00)^{d}$ & $53.0(31.82)$ & $43.8(34.72)$ \\
\hline Role physical & $84.3(21.28)$ & $68.8(8.84)$ & $50.3(28.09)$ & $51.6(28.69)$ \\
\hline Bodily pain & $84.5(18.94)$ & $75.0(0.00)^{d}$ & $53.6(26.8 I)$ & $46.9(20.86)$ \\
\hline General health & $78.9(16.35)$ & $60.0(0.00)^{d}$ & $52.7(22.34)$ & $53.1(25.49)$ \\
\hline Vitality & $62.7(17.92)$ & $37.5(17.68)$ & $37.5(22.93)$ & $31.3(29.12)$ \\
\hline Social functioning & $91.8(17.38)$ & $75.0(0.00)^{d}$ & $70.2(27.74)$ & $65.6(29.69)$ \\
\hline Role emotional & $88.2(19.31)$ & $68.8(8.84)$ & $69.6(27.77)$ & $70.3(26.67)$ \\
\hline Mental health & $74.3(18.70)$ & $75.0(17.68)$ & $59.8(24.3 \mathrm{I})$ & $60.9(15.58)$ \\
\hline
\end{tabular}

Notes: ${ }^{2}$ Among those with at least one reported comorbidity ( $n=33$ for FM-CWP- $\rightarrow$ FM-CWP-; $=2$ for FM-CWP $-\rightarrow F M+C W P+; n=40$ for FM-CWP+ $\rightarrow$ FM-CWP + ; $=8$

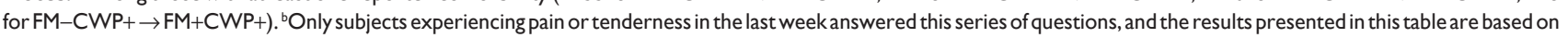
these counts: number experiencing pain or tenderness over past week ( $n=37$ for FM-CWP- $\rightarrow F M-C W P-; n=2$ for FM-CWP $-\rightarrow F M+C W P+; n=42$ for FM-CWP+ $\rightarrow F M-C W P+$;

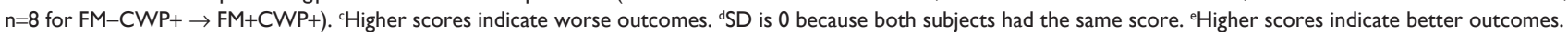
Abbreviations: BPI-SF, Brief Pain Inventory -Short Form; CWP+, chronic widespread pain - positive; CWP-, chronic widespread pain - negative; FM+, diagnosed with fibromyalgia; FM-, not diagnosed with fibromyalgia; MOS-SS, Medical Outcomes Study - Sleep Scale; SF-I 2v2, I2-Item Short-Form Health Survey, Version 2. 
Table S2 Comparison of clinical and patient-reported outcomes at baseline: subjects who transitioned out of the FM+CWP+ group versus subjects who remained in the FM+CWP+ group at follow-up

\begin{tabular}{|c|c|c|c|}
\hline Outcome, mean (SD) & $\begin{array}{l}\text { FM+CWP+ } \rightarrow \\
\text { FM-CWP- }(n=I I)\end{array}$ & $\begin{array}{l}\text { FM+CWP+ } \rightarrow \\
\text { FM-CWP+ }(n=9)\end{array}$ & $\begin{array}{l}\text { FM+CWP+ } \rightarrow \\
F M+C W P+(n=56)\end{array}$ \\
\hline Time since FM diagnosis, months ${ }^{\mathrm{a}}$ & $2.4(7.52)$ & I5.6 (46.8I) & $64.0(92.30)$ \\
\hline Number of tender points & $13.8(4.14)$ & $10.9(4.17)$ & $14.7(3.35)$ \\
\hline Number of comorbidities & $4.3(2.33)$ & $3.9(3.92)$ & $5.2(2.99)$ \\
\hline Among those with $\geq 1^{b}$ & $4.3(2.33)$ & $5.0(3.74)$ & $5.3(2.93)$ \\
\hline Modified ACR 2010 criteria score $^{c}$ & $16.2(5.62)$ & $17.1(4.62)$ & $19.0(5.66)$ \\
\hline BPI-SF Pain Severity Index ${ }^{c, d}$ & $4.6(1.35)$ & $5.0(2.57)$ & $5.4(1.92)$ \\
\hline Pain at worst, past 24 hours & $6.6(1.12)$ & $6.1(3.02)$ & $6.8(2.01)$ \\
\hline Pain at least, past 24 hours & $2.5(1.75)$ & $3.3(2.18)$ & $3.7(2.33)$ \\
\hline Average pain & $4.7(1.49)$ & $4.8(2.44)$ & $5.4(1.93)$ \\
\hline Pain right now & $4.6(1.91)$ & $5.7(3.32)$ & $5.7(2.24)$ \\
\hline BPI-SF Pain Interference Index ${ }^{c, d}$ & $5.3(2.54)$ & $4.9(2.62)$ & $6.2(2.29)$ \\
\hline General activity & $4.9(2.84)$ & $5.1(3.18)$ & $5.8(2.49)$ \\
\hline Mood & $5.0(3.44)$ & $4.4(3.05)$ & $5.8(2.5 \mathrm{I})$ \\
\hline Walking ability & $4.4(3.01)$ & $5.3(3.00)$ & $6.2(3.15)$ \\
\hline Normal work & $5.6(1.96)$ & $5.1(2.85)$ & $6.4(2.72)$ \\
\hline Relations with other people & $4.0(3.35)$ & $3.8(2.99)$ & $4.9(3.02)$ \\
\hline Sleep & $7.2(2.40)$ & $5.3(3.20)$ & $7.3(2.64)$ \\
\hline Enjoyment of life & $5.6(3.14)$ & $4.9(2.57)$ & $6.8(2.44)$ \\
\hline MOS-SS Overall Sleep Problem Index & $58.0(17.11)$ & $48.3(12.72)$ & $59.9(15.54)$ \\
\hline \multicolumn{4}{|l|}{$S F-12 v 2^{e}$} \\
\hline Physical Component Summary & $37.5(10.21)$ & $34.7(11.46)$ & $31.6(10.76)$ \\
\hline Mental Component Summary & $42.9(14.49)$ & $43.0(7.75)$ & $41.5(10.12)$ \\
\hline Physical function & $40.9(30.15)$ & $47.2(34.11)$ & $29.9(3 I .4 I)$ \\
\hline Role physical & $44.3(26.44)$ & $43.1(21.75)$ & $33.5(26.98)$ \\
\hline Bodily pain & $52.3(20.78)$ & $50.0(27.95)$ & $36.6(23.82)$ \\
\hline General health & $57.3(29.10)$ & $33.9(21.18)$ & $41.3(26.31)$ \\
\hline Vitality & $36.4(20.50)$ & $16.7(17.68)$ & $21.4(23.56)$ \\
\hline Social functioning & $50.0(35.36)$ & $58.3(25.00)$ & $50.0(26.97)$ \\
\hline Role emotional & $67.0(32.25)$ & $70.8(21.65)$ & $61.2(25.4 I)$ \\
\hline Mental health & $54.5(26.38)$ & $56.9(15.45)$ & $50.7(19.86)$ \\
\hline
\end{tabular}

Notes: aSubjects who reported being diagnosed prior to baseline were reevaluated by the site physician to confirm FM diagnosis. If the prior diagnosis was confirmed, the subject-reported month and year of the initial diagnosis were used. For subjects diagnosed for the first time at baseline, time since diagnosis was 0 months. ${ }^{b}$ Among those with at least one reported comorbidity ( $n=1$ I for FM+CWP+ $\rightarrow$ FM-CWP-; $n=7$ for FM+CWP+ $\rightarrow$ FM-CWP+; $=55$ for FM+CWP+ $\rightarrow$ FM+CWP+). ${ }^{\text {Higher }}$ scores indicate worse outcomes. ${ }^{d}$ Only subjects experiencing pain or tenderness in the last week answered this series of questions, and the results presented in this table are based on these counts: number experiencing pain or tenderness over past week ( $n=1$ I for FM+CWP $+\rightarrow \mathrm{FM}-\mathrm{CWP}-; \mathrm{n}=9$ for $\mathrm{FM}+\mathrm{CWP}+\rightarrow \mathrm{FM}-\mathrm{CWP}+$; $=56$ for $\mathrm{FM}+\mathrm{CWP}+\rightarrow$

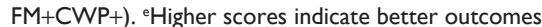

Abbreviations: ACR, American College of Rheumatology; BPI-SF, Brief Pain Inventory - Short Form; CWP+, chronic widespread pain - positive; CWP-, chronic widespread pain - negative; FM+, diagnosed with fibromyalgia; FM-, not diagnosed with fibromyalgia; MOS-SS, Medical Outcomes Study - Sleep Scale; SF-I2v2, I2-Item Short-Form Health Survey, Version 2.

\section{Publish your work in this journal}

The Journal of Pain Research is an international, peer-reviewed, open access, online journal that welcomes laboratory and clinical findings in the fields of pain research and the prevention and management of pain. Original research, reviews, symposium reports, hypothesis formation and commentaries are all considered for publication.

\section{Dovepress}

The manuscript management system is completely online and includes a very quick and fair peer-review system, which is all easy to use. Visit http://www.dovepress.com/testimonials.php to read real quotes from published authors. 